\title{
COVID-19 AND RESPIRATORY PROTECTION FOR HEALTHCARE PROVIDERS
}

\author{
SARKIS SOZKES ${ }^{1}$ and SERDA SOZKES ${ }^{2}$ \\ ${ }^{1}$ Namik Kemal University, Tekirdag, Turkey \\ Corlu Faculty of Engineering, Biomedical Engineering Biomaterials Department \\ ${ }^{2}$ Saglik Bakanligi Catalca Ilyas Colak Public Hospital Istanbul, Istanbul, Turkey \\ Intensive Care Unit and Reanimation Department
}

\begin{abstract}
This article has investigated the considerations of healthcare facilities to utilize reusable respirators as an alternative to disposable respirators during the COVID-19 pandemic. The decision to choose specific equipment should be based on the protection factors and also on the overall analysis of given conditions. International scientific databases, such as Web of Science, PubMed and MedLine, were searched on May 5, 2020, with the following key words: COVID-19, respiratory protection, surgical masks, filtering facepiece respirators (FFRs) and disposable respirators. The differences between various respiratory protective equipment, i.e., surgical masks, respirators such as FFRs, elastomeric half-facepiece respirators, elastomeric full-facepiece respirators and powered air-purifying respirators (PAPRs), were compared. Reusable elastomeric respirators (RERs) may provide a better adaptation to the face and may be more stable when used by healthcare providers (HCPs). Protection factors were found to be higher in FFRs compared to surgical masks. While FFRs provide a one-tenth decrease in the inhaled aerosol concentration, PAPRs diminish the inhaled aerosol up to one-twenty-fifth. Even with some full-face PAPRs and helmets, the protection factor assigned by the Occupational Safety and Health Administration can reach a value up to 1000 . For HCPs, the evidence shown in this article provides an additional support for the utilization of RERs. Such equipment might be less prone to leakages, can provide a better fit, and indicates a better stability compared to disposable FFRs (N95 and similar). By providing higher protection factors, reusable elastomeric respirators are recommended to be used by HCPs under controlled cleaning and disinfection protocols. Int J Occup Med Environ Health. 2021;34(2):307-18
\end{abstract}

Key words:

occupational health services, respiratory protective devices, pandemics, respirators, healthcare providers, occupational health of physicians

\section{INTRODUCTION}

Preliminary reports from Wuhan informed the World Health Organization (WHO) of the detection of a new type of coronavirus in several patients. This novel coronavirus was named as SARS-CoV-2, and on February 11, 2020, viral pneumonia caused by this virus was termed COVID-19 [1]. On March 11, 2020, after COVID-19 had spread worldwide, WHO declared the infection a pandemic.
When the novel SARS-CoV-2 was known to be transmitted possibly through inhalation, the respiratory protection of healthcare providers (HCPs) became of utmost importance. First, to better understand the available materials for the protection of respiratory airways, it is important that the relevant terminologies be defined so that differences between various types of equipment could be properly understood.

Even though all pieces of respiratory protective equipment are often called masks, technically, there are differ-

Received: May 27, 2020. Accepted: October 6, 2020.

Corresponding author: Sarkis Sozkes, Namik Kemal University, Corlu Faculty of Engineering, Biomedical Engineering Biomaterials Department, Silahtaraga Mahallesi, Universite 1. Sokak No. 1 Corlu 59860, Tekirdag, Turkey (e-mail: ssozkes@nku.edu.tr). 
a)

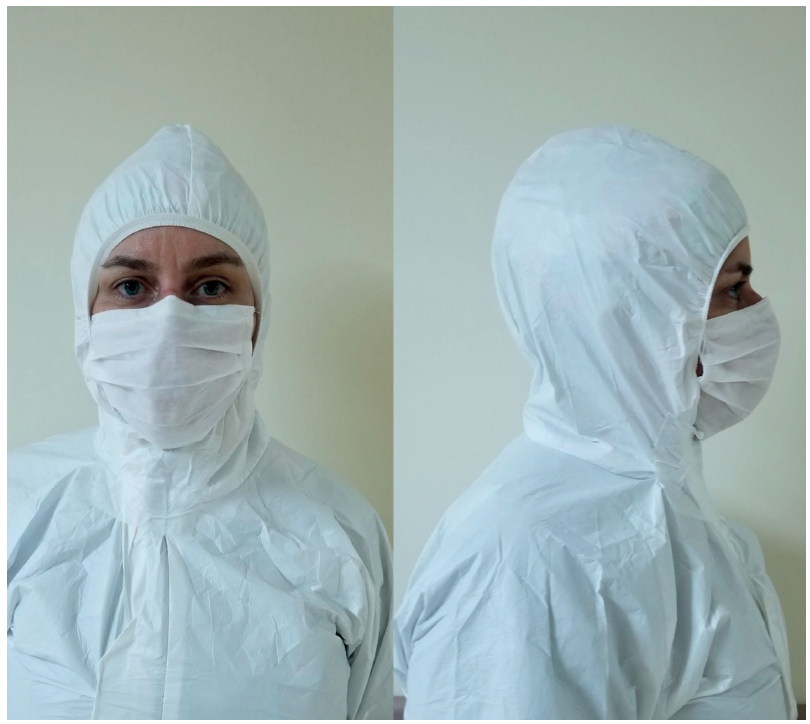

Figure 1. A surgical mask (SOLYCARE ${ }^{\mathrm{TM}}$, Turkey): a) front view, b) lateral view

ences between a mask and a respirator. Surgical masks provide one-sided protection mainly to patients but not to HCPs. Surgical masks are made up of different pieces of fabric to cover the nose and mouth, and to provide the protection to patients from particulate aerosols and body fluids from HCPs. Surgical masks that have a loose fit provide one-sided protection and are not sufficient for protecting the wearer (Figure 1). Unfortunately, only few types of surgical masks are tested for quality whereas the rest do not have a calculated protection factor. Surgical masks are mostly described based on the number of layers they have, such as 2-layered or 3-layered surgical masks. Quality surgical masks mostly have a triple-layer design; the 2 outer layers are made of non-woven fabric, whereas the middle layer is made through melt-blowing. This middle melt-blown layer of the mask defines its filtering capability. However, surgical masks are not always evaluated based on that parameter.

Unlike surgical masks, filtering facepiece respirators (FFRs) are designed to protect the wearer. In hospitals, the use of FFRs protects HCPs. Additionally, FFRs provide a) b)

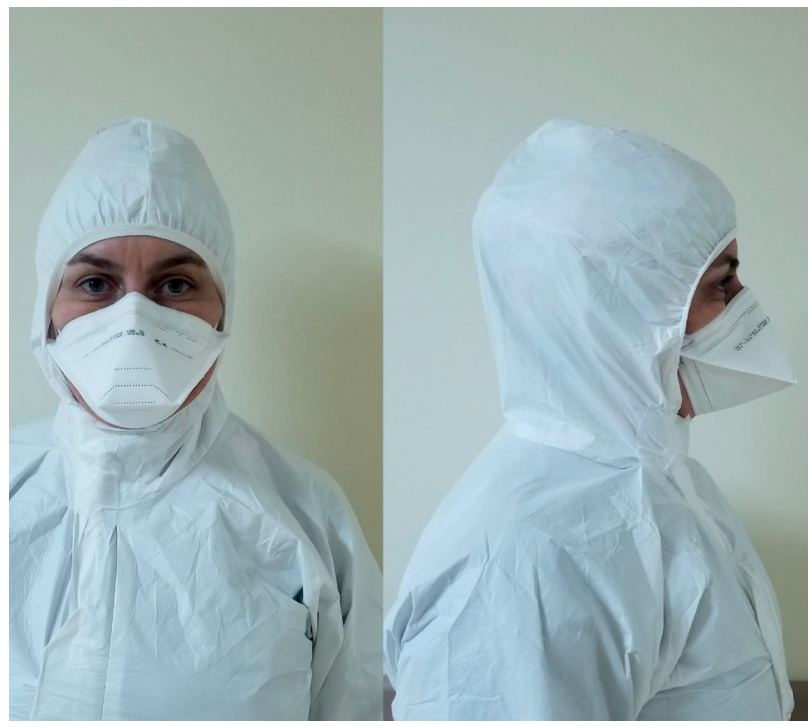

Figure 2. A FFP2 respirator (MFA ${ }^{\mathrm{TM}} \mathrm{Z}-267$, Turkey): a) front view, b) lateral view

a better seal and fit than surgical masks; and tight-fitting facepieces generally have a higher protection factor. In general, FFRs are classified into 2 major types: valved and non-valved. Non-valved FFRs provide a sufficient respiratory protection to both HCPs and patients. In both types of FFRs, the air that passes through the respirator is filtered in both directions: inwards and outwards (Figure 2). These respirators achieve a good seal when properly worn. Moreover, the safety of these respirators is based on the standard security rating. They are also available as disposable respirators or reusable elastomeric respirators (RERs).

The Center for Disease Control and Prevention (CDC) has published a guidance against COVID-19 and advised the use of N95 respirators as standard protective equipment. This standard suggests that an N95 or better respirator, such as $\mathrm{N} 99$ or N100, is acceptable for the protection against the COVID-19 pandemic. The safety standard of the N95 respirator, which is a disposable respirator, is managed by the National Institute for Occupational Safety and Health (NIOSH) in the USA. 
In Europe, different standard coding is used for filtering facepieces (FFPs) and particle filters. The European EN 149:2001+A1:2009 standard certifies FFP masks with increasing levels of protection scores marked as 1, 2, or 3; these scores correspond to the respirators labeled FFP1, FFP2, or FFP3. The European EN 149:2001+A1:2009 standard also specifies the particle protection of respiratory protective equipment. The other EN 143 standard covers particle filters and classifies them based on their $\mathrm{P} 1 / \mathrm{P} 2 / \mathrm{P} 3$ ratings. These 2 standards are both controlled and maintained by the European Committee for Standardization.

China has similar standards for FFP coding as the USA, with the Chinese KN95 standard being equivalent to the U.S. N95 standard. These standards are described by the Standardization Administration of China created on March 27, 2006, and the GB 2626-2006 standard. The GB 2626-2006 standard explains the technical requirements, testing methods, and the identification of particle respirators. These Chinese standards are employed against all types of particles for non-powered air-purifying respiratory protective equipment. In theory, the U.S. N95, European FFP2, and Chinese KN95 respirators have equivalent specifications. However, as the materials used in manufacturing and testing protocols differ in various countries, which makes standardization complicated, there is no certainty as to whether all the respirators provide equivalent protection at certain protection levels established in each country.

Reusable elastomeric respirators are preferred mostly by workforces in the industry, military, construction, and painting professions for respiratory protection. These respirators have a good fit and seal, which provides sufficient protection. These respirators are manufactured from flexible materials which are perfect for providing a good seal; if regularly maintained, they can be used for long periods, i.e., years [2].

For long-term use, the equipment must be stored under conditions as specified by the manufacturer, any deformed parts must be replaced with original spare parts, and care has to be provided for cleaning and disinfection. While the whole body of RERs can last for many years, the removable filters or cartridges must be replaced regularly to ensure respiratory protection. The protective performance of RERs is highly affected by its capacity to provide a proper face seal; variations in its protective performance have been attributed to an insufficient seal [3]. Since the face seal is a highly important factor in the performance of respirators, the Occupational Safety and Health Administration (OSHA) in the USA requires fit testing of respirators prior to their extended use [4].

Air-purifying respirators which have air pressure sensors and control airflow every second are called powered airpurifying respirators (PAPRs). With these sensors, the air level inside the respirator is maintained at a pre-assigned value during use. With a powered motor, air passes from the filter or cartridges and stays inside the respirator. The airflow inside PAPRs provides efficient protection. The assigned protection factor (APF) and the face seal provided by PAPRs are higher and better, respectively, than those of RERs and FFRs. During the COVID-19 pandemic, HCPs work in environments with aerosols that may contain SARS-CoV-2 and, thus, PAPRs have been proposed to be used as respiratory protection equipment. There are different types of PAPRs, such as half-facepiece, full-facepiece, hood, or helmet. These respirators can achieve a rating of 1000 APF in testing, which indicates better effectiveness than that of FFRs.

In Wuhan in December 2019, bronchial samples were analyzed and SARS-CoV-2-infected cultures were examined under light microscopy, and the size of the virus was found to range 0.06-0.14 $\mu \mathrm{m}$ [5]. While COVID-19 has come to affect all continents in the world, the protection efficiency of various respirators against SARS-CoV-2 and biological agents is a question to be answered by scientists. The most important question that needs to be addressed is whether respirators can filter small particles such as spores, bac- 
Table 1. Classification of various microorganisms based on their most penetrating particle size (MPPS) [5-11,13-15]

\begin{tabular}{lll}
\hline \multicolumn{1}{c}{ Physical size } & \multicolumn{1}{c}{ Microorganism } & \multicolumn{1}{c}{ Disease } \\
\hline$<0.3 \mu \mathrm{m}$ MPPS & Hepatitis B Virus $(\mathrm{HBV})$ & viral hepatitis \\
$0.04 \mu \mathrm{m}$ & Adenoviridae & respiratory disease and multi-organ disease \\
$0.07-0.09 \mu \mathrm{m}$ & Bunyaviridae & hantavirus \\
$0.08-0.012 \mu \mathrm{m}$ & Orthomyxoviridae & flu pandemic and influenza \\
$0.08-0.012 \mu \mathrm{m}$ & Filoviridae & Ebola \\
$0.08 \mu \mathrm{m}$ & Coronaviridae & SARS-CoV-2 \\
$0.12 \mu \mathrm{m}$ & Variola vera & red plague \\
$0.14-0.26 \mu \mathrm{m}$ & & \\
$>0.3 \mu \mathrm{m} \mathrm{MPPS}$ & Bacillus anthracis spore & anthrax \\
$1.0-1.5 \mu \mathrm{m}$ & Mycobacterium tuberculosis & tuberculosis \\
$1.0-5.0 \mu \mathrm{m}$ & Bacillus species & bloodstream infection \\
$3.0 \mu \mathrm{m}$ & Staphylococcus aureus & pneumonia, meningitis \\
$13.3-15.7 \mu \mathrm{m}$ & &
\end{tabular}

teria, or viruses [6]. In Table 1, the sizes of some micro organisms are provided [5-11,13-15].

\section{METHODS}

Literature search for the journals included in the international scientific databases, such as Web of Science, PubMed and MedLine, were searched on May 5, 2020, with the following key words: COVID-19, respiratory protection, surgical masks, FFRs and disposable respirators. The differences between various respiratory protective equipment, i.e., surgical masks, respirators such as FFRs, elastomeric half-facepiece respirators, elastomeric full-facepiece respirators and PAPRs, were compared. While using the databases, an advanced option with "or" and "and" choices was used. The shortlisted articles were evaluated and selected in terms of relevance to this study design, with the impact of respiratory protection with surgical masks and FFRs.

Particles such as body fluids or dust may also be carriers of particles. For example, the particles produced when coughing or speaking may quickly form droplet nuclei, which were previously reported to be around $20 \mu \mathrm{m}$ [7]. In an- other report on the influenza virus, samples were obtained from expired air [8]. Another study on the size of Mycobacterium tuberculosis reported that the size of the droplet nuclei for this bacterium is approximately $1-5 \mu \mathrm{m}[8,9]$. Hospital room air containing the particles spread from patients infected with influenza was evaluated, and the size of the virus ranged $1-4 \mu \mathrm{m}$ [10]. A fiber of 1-100 $\mu \mathrm{m}$ forms a diagonal stripe, creating layers of the filter structure in which air passes through, and the breathing ability of the respirators is calculated according to the inter-fiber spaces [11]. While air passes through these filters, particles can be trapped in the filters or pass through due to forces such as gravity, impaction, inertial impaction, spread, Coulomb interaction, diffusion, or interception [11].

Airborne particles of $>100 \mu \mathrm{m}$ can be filtered with respect to their velocity and affected by the gravity settlement, whereas many of the particles in the respiratory tract are very small particles that are not affected by gravity. Particles of $>0.6 \mu \mathrm{m}$ in diameter were mostly filtered by interception or inertial impaction [12]. When a particle cannot pass through fibers because of its inertia, impaction to the fiber occurs. Interception occurs when airborne par- 
ticles are captured by the fibers [12]. For airborne particles of $\leq 0.1 \mu \mathrm{m}$, diffusion was reported, as air molecules collide with particles and aerodynamics forces them to be filtered by the fibers due to their random movements [12]. As air passes through the filters, the particles are captured by various mechanisms. It has been found that the biggest challenge is not the interception of particles of extremely small sizes, but the interception of the particles sized approximately $0.05-0.5 \mu \mathrm{m}$ [11]. The latter are not large enough to be intercepted by diffusion, and not small enough to be intercepted by inertial impaction or impaction [11]. Consequently, respirators are measured according to their efficiency in intercepting particles of $\geq 0.3 \mu \mathrm{m}$, which is also defined as the most penetrating particle size (MPPS) [13].

There is a phenomenon called Brownian motion (BM), in which particles of $<0.3 \mu \mathrm{m}$ are intercepted easily as they do not travel in the air in a defined direction due to their relatively lower mass than that of air [14]. When these particles collide in the air with $\mathrm{O}_{2}$ or $\mathrm{N}$, they change direction in an uncontrolled pattern and are easily intercepted by fibers [15]. Based on this research, not only the large particles were easy to filter but also the smallest size particles due to BM [15]. Table 1 classifies various microorganisms according to MPPS.

With BM in mind, one can assume that the respirators tested to the $0.3-\mu \mathrm{m}$ particle size can intercept SARS$\mathrm{CoV}-2$, which is around $0.12 \mu \mathrm{m}$ [5], to the efficiency level assigned by the authorities. This is due to the facts that are known from previous published studies. The research conducted during the ongoing pandemic will deliver information about the protection level provided by respirators against SARS-CoV-2. Until then, the protection levels are assumed based on the previous knowledge according to publications and international standards. For example, the interception of particles of $0.3 \mu \mathrm{m}$ with an FFP2 respirator, i.e., the worse-case scenario, would be $94 \%$, whereas $99.7 \%$ of such particles would be filtered with an FFP3 respirator. Filtration efficiency requirements and stan- dards with APFs or nominal protection factors (NPFs) are compared in Table 2, including the efficiency requirements for various countries $[2-4,13]$.

There are 2 types of FFRs depending on whether they have or do not a valve. Air inhalation is the same in both types of these respirators, whereas exhalation is easier in those with a valve (Figure 3). Valved FFRs are more appropriate for use in industrial plants as there is no filtration in exhalation and the protection is required only for the users. During the COVID-19 pandemic, the use of valved FFRs with a one-sided filtering mechanism might put others that the wearer interacts with at risk of infection. When valved FFRs are needed to create double-sided protection, a piece of cloth or a surgical mask can be additionally worn for partially filtering the air exhalation (Figure 4). Cartridges are included in RERs, and filtering mechanisms occur in these removable cartridges. There are different models available for RERs with 1 or 2 cartridges (Figure 5), and these can be half- or full-facepiece respirators (Figure 6). The number of cartridges in use is more of a user's choice for the design; however, the filtering capacity is also important, and the particle filters which can be used in hospitals are labeled with letter "P" in relation to relative filtration efficiency standards (Table 2). This symbol stands for particulate filtering and numbers 1, 2, and 3 are the efficiency levels; more specifically, P1 corresponds to FFP1, P2 corresponds to FFP2, and P3 corresponds to FFP3.

The protection factor is defined as the protection level provided by a certain type of the respirator when worn according to the manufacturer's recommendations; a proper fit must be achieved for leakage control. The protection factor indicates the protection provided by a respirator compared to a situation when nothing is worn. The NPF corresponds to the maximum percentage of the total inward leakage (TIL) permitted by European standards (EN) for a given class of respirators. As NPFs were developed through laboratory tests by trained individuals, they 
Table 2. Filtration efficiency requirements and standards with assigned or nominal protection factors for respiratory protective equipment $[2-4,13,25,26,28,29,32]$

\begin{tabular}{|c|c|c|c|c|c|}
\hline Equipment & Origin & Standard & $\begin{array}{c}\text { Filter } \\
\text { classification }\end{array}$ & Efficiency & $\mathrm{APFs}^{*} / \mathrm{NPFs}^{*}$ \\
\hline \multirow[t]{9}{*}{ FFR } & \multirow[t]{3}{*}{ USA } & \multirow[t]{3}{*}{ NIOSH 42/CFR 84} & N95 & $\geq 95 \%$ & 4 APFs \\
\hline & & & N99 & $\geq 99 \%$ & $10 \mathrm{APFs}$ \\
\hline & & & N100 & $\geq 99.97 \%$ & 20 APFs \\
\hline & \multirow[t]{3}{*}{ Europe } & \multirow[t]{3}{*}{ EN 149:2001 } & FFP1 & $\geq 80 \%$ & 4 NPFs \\
\hline & & & FFP2 & $\geq 94 \%$ & 12 NPFs \\
\hline & & & FFP3 & $\geq 99 \%$ & $50 \mathrm{NPFs}$ \\
\hline & \multirow[t]{3}{*}{ China } & \multirow[t]{3}{*}{ GB 2626-2006 } & $\mathrm{KN} / \mathrm{KP} 90$ & $\geq 90 \%$ & n.a. \\
\hline & & & $\mathrm{KN} / \mathrm{KP} 95$ & $\geq 95 \%$ & n.a. \\
\hline & & & $\mathrm{KN} / \mathrm{KP} 100$ & $\geq 99.97 \%$ & n.a. \\
\hline \multirow{3}{*}{$\begin{array}{l}\text { Reusable elastomeric } \\
\text { half-facepiece } \\
\text { respirator }\end{array}$} & \multirow[t]{3}{*}{ Europe } & \multirow[t]{3}{*}{ EN 143:2000/ EN 140:1999/ EN 136:1998 } & P1 & $\geq 80 \%$ & 4 NPFs \\
\hline & & & $\mathrm{P} 2$ & $\geq 94 \%$ & 12 NPFs \\
\hline & & & P3 & $\geq 99.95 \%$ & $48 \mathrm{NPFs}$ \\
\hline \multirow{3}{*}{$\begin{array}{l}\text { Reusable elastomeric } \\
\text { full-facepiece } \\
\text { respirator }\end{array}$} & \multirow[t]{3}{*}{ Europe } & \multirow[t]{3}{*}{ EN 143:2000/ EN 140:1999/ EN 136:1998 } & $\mathrm{P} 1$ & $\geq 80 \%$ & $5 \mathrm{NPFs}$ \\
\hline & & & $\mathrm{P} 2$ & $\geq 94 \%$ & 16 NPFs \\
\hline & & & $\mathrm{P} 3$ & $\geq 99.95 \%$ & $1000 \mathrm{NPFs}$ \\
\hline \multirow{3}{*}{$\begin{array}{l}\text { PAPR with a hood } \\
\text { or a helmet }\end{array}$} & \multirow[t]{3}{*}{ Europe } & \multirow{3}{*}{$\begin{array}{l}\text { EN } 12941 \text { (TH1: inward leakage max } 10 \% \text {; } \\
\text { TH2: inward leakage max } 2 \% \text {; } \\
\text { TH3: inward leakage max } 0.2 \% \text { ) HEPA }\end{array}$} & TH1 & $\geq 99.97 \%$ & 10 NPFs \\
\hline & & & TH2 & $\geq 99.97 \%$ & $50 \mathrm{NPFs}$ \\
\hline & & & TH3 & $\geq 99.97 \%$ & $500 \mathrm{NPFs}$ \\
\hline \multirow{3}{*}{$\begin{array}{l}\text { PAPR with a tight- } \\
\text { fitting mask }\end{array}$} & \multirow[t]{3}{*}{ Europe } & \multirow[t]{3}{*}{ EN 12942, HEPA } & TM1 & $\geq 99.97 \%$ & $20 \mathrm{NPFs}$ \\
\hline & & & TM2 & $\geq 99.97 \%$ & 200 NPFs \\
\hline & & & TM3 & $\geq 99.97 \%$ & 2000 NPFs \\
\hline
\end{tabular}

APFs - assigned protection factors; FFR - filtering facepiece respirator; HEPA - high-efficiency particulate air; NPFs - nominal protection factors; PAPR - powered air-purifying respirator. n.a. - not available.

* Europe uses NPFs, while USA uses APFs.

might not represent the true protection factor that one must achieve in a given workplace; these existing values are used more as a reference. In contrast, APFs are realistic factor values that translate to a situation when respirators are properly used. The APF values are more realistic than the NPF values as they were obtained through simulated workplace testing by appointed groups at national levels; however, the APF values may vary greatly between countries. These values should be noted (or are required to be used) when selecting respirators (Table 2).
Finally, PAPRs are slightly different from the previously analyzed respirators in this article. These respirators have a fan assistance that regulates air pressure inside the respirator and provides a positive air pressure. As PAPRs offer comfortable respiratory protection and integrated protection against multiple hazards, they help in ensuring respiratory, head, face, eye, and hearing protection. Some all-in-one kits designed for HCPs have maintenance-free disposable head covers designed to help protect HCPs from airborne particles without compromising comfort or flexibility. 
a)

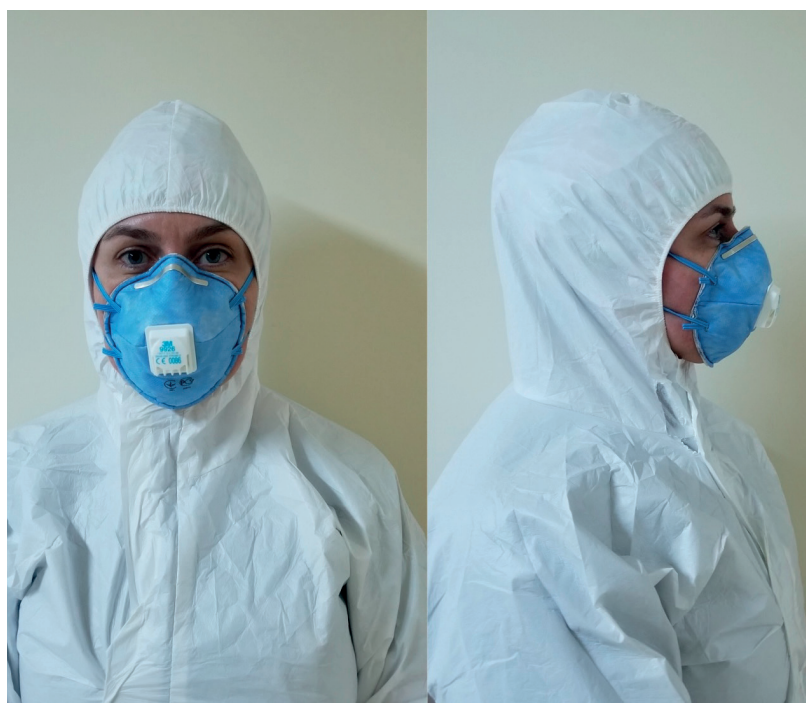

Figure 3. A valved FFP2 respirator ( $3 \mathrm{M}^{\mathrm{TM}}$ 9926, USA):

a) front view, b) lateral view

a)

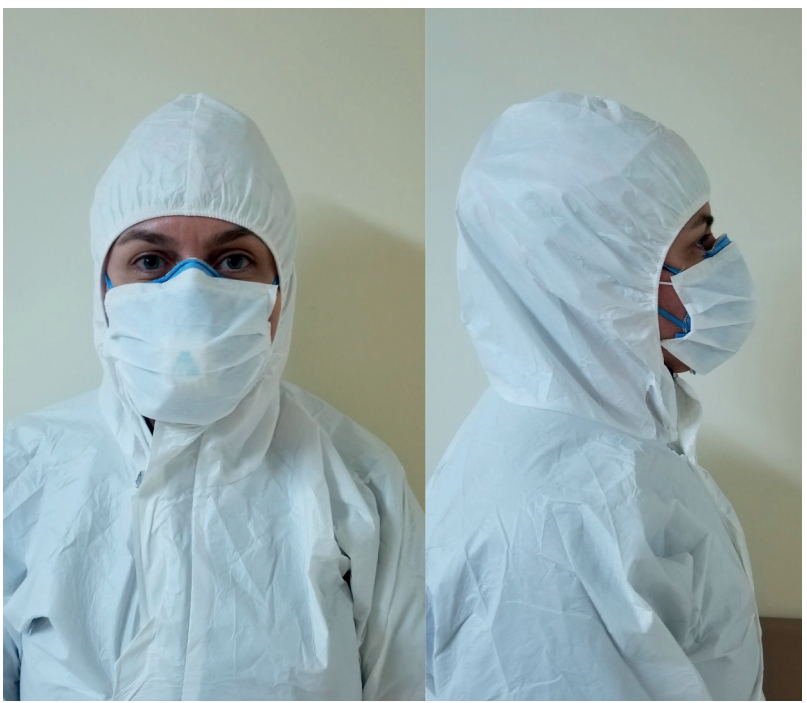

Figure 4. A valved filtering facepiece respirator (3M ${ }^{\mathrm{TM}} 9926$, USA) + a surgical mask FFP2 (SOLYCARE ${ }^{\mathrm{TM}}$, Turkey) :

a) front view, b) lateral view

\section{RESULTS}

Quality surgical masks mostly have a triple-layer design; the 2 outer layers are made of non-woven fabric and the middle layer is made through melt-blowing. This meltblown layer defines the filtering capability of the mask and is mainly made of plastic turned into a structure with minor filaments [16]. Additional features, such as an electrostatic field, can be incorporated during the manufacturing phase of surgical masks [16]. It has been reported that surgical masks with a melt-blown layer alone have a lower filtration

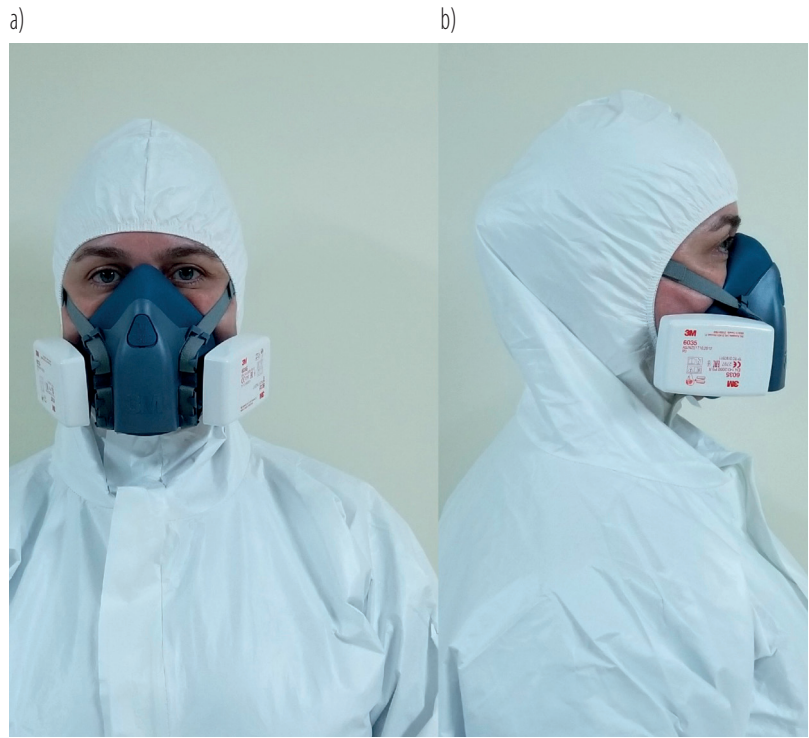

Figure 5. A reusable elastomeric half-facepiece respirator P3 Filters $6035\left(3 \mathrm{M}^{\mathrm{TM}} 7502\right.$, USA): a) front view, b) lateral view

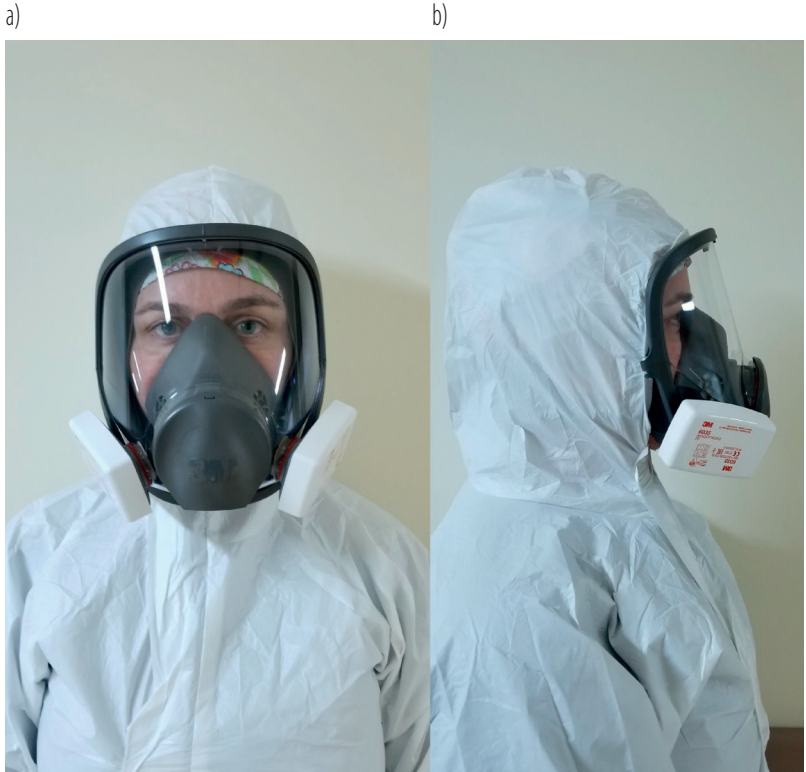

Figure 6. A reusable elastomeric full-facepiece respirator P3 Filters $6035\left(3 \mathrm{M}^{\mathrm{TM}} 6800, \mathrm{USA}\right)$ : a) front view, b) lateral view 
efficiency than those with electrostatic field; these masks are also reported to be stronger [16].

It is not logical to expect that all surgical masks are of the same filtering quality, as surgical masks are not classified by international standards as respirators. There are testing methods that are described by the American Society of Testing and Materials (ASTM) for analyzing surgical masks. According to ASTM, surgical masks are listed in 3 levels: 1 indicates the minimum and 3 indicates the maximum level of barrier protection. However, regardless of the barrier level specified, none of the surgical masks protects HCPs from SARS-CoV-2. Surgical masks are mainly used for protecting patients from HCPs and they provide no respiratory protection (Figure 1).

Currently, the COVID-19 pandemic is ongoing and there is no particular research comparing the filtering capacity of surgical masks and respirators. However, research data can be considered to provide guidance in protecting people against SARS-CoV-2, which is similar in size to the influenza virus; both viruses are transmitted in similar ways and cause infections in the respiratory system [17]. Radonovich et al. [18] conducted a randomized comparison of the effectiveness of surgical masks and respirators. In hospitals at 7 different locations in the USA, during the 12-week period of influenza and viral infections, the participants were grouped into the N95 group, which consisted of those who wore respirators, and the medical mask group consisting of those who wore surgical masks. From the 2862 participants in total, 2371 were reported to have completed the study [18]. Influenza infections were reported in 207 members of the N95 group and in 193 members of the medical mask group. Acute respiratory disease was reported in 1556 and 1711 participants of the N95 group and the medical mask group, respectively. Respiratory infections were reported in 679 and 745 participants of the N95 group and the medical mask group, respectively. Other respiratory disease infections occurred in different participants in each group, and all study data were analyzed. Radonovich et al. [18] concluded that among the HCPs who wore N95 respirators and surgical masks, no significant difference was implied.

Another study conducted by Loeb et al. [19] analyzed the protection provided by surgical masks compared to N96 respirators utilized by HCPs during the influenza outbreak. In September-December 2008 in Ontario, Canada, 225 nurses were advised to use surgical masks, whereas other 211 were requested to use N95 respirators. During the assigned period, 50 nurses in the surgical mask group and 48 nurses in the N95 respirator group were infected with influenza. The results of the study by Loeb et al. [19] also did not indicate a significant difference in the occurrence of influenza infections depending on whether the nurses used surgical masks or N95 respirators. In the 2006-2007 winter season, a randomized comparative trial was conducted by MacIntyre et al. [20] to compare whether the use of masks by the participants prevented influenza. In this study, 286 participants were included in a comparative trial, and it was reported that the use of masks decreased the infection risk. The authors concluded that the use of surgical masks could have decreased the transmission of the disease and would be greater during a pandemic.

Lai et al. [21] mentioned the control of spread of 2019$\mathrm{nCoV}$ and strongly described COVID-19 as a global threat, especially to HCPs. Until an effective evidence-based treatment modality or vaccination is found, all preventive protection measures are persistently recommended. MacIntyre and Chughtai [22] recently reviewed 19 articles on the utilization of respiratory protective equipment. Eight of these articles were in community settings, 6 were in hospital settings, and 5 were taken as source control. The authors reported that if HCPs had worn respirators uninterruptedly during their work shifts, the respirators could have provided effective protection. MacIntyre and Chughtai [22] further reported that surgical masks were not protective and that textile-fabricated cloth masks were 
even more inadequate, but they simultaneously stated that surgical masks could be utilized beneficially for eliminating the transmission in the community as a preventive measure of cross-infection. The review article clearly supports the continued use of respiratory protective equipment and emphasizes that HCPs could be protected by respirators from aerosols that may contain SARS-CoV-2.

During the COVID-19 pandemic, with the increasing demand and shortage of protective respiratory materials, hospitals are considering the use of RER devices as an alternative to FFP2, or equivalent disposable respirators. The protection factor studies described by Liverman et al. [2] demonstrated that RERs, with their good fit and seal characteristics, provide a superior and more efficient protection than disposable FFRs [23-26]. It was reported that the protection provided by RERs was $60 \%$ higher than that of disposable FFRs in healthcare settings [2,26]. In addition, P100 disposable FFPs and P3 (EU)/P100 (USA) RERs were tested against nanoparticles of the same sizes for performance in agricultural settings, with RERs being reported to provide a higher protection factor than disposable FFRs [25]. Moreover, CDC has recommended reusable FFRs for respiratory protection of HCPs, and advised on the utilization of products approved by the Food and Drug Administration (FDA) and NIOSH [27]. With a good face seal, half- or full-facepiece RERs were expected to diminish the virus concentration to one-tenth of the original concentration.

In comparison to FFRs providing a 10-fold decrease in inhaled aerosol concentration, PAPRs diminish the inhaled aerosol by up to one-twenty-fifth. Even with some full-facepiece PAPRs and helmets, the APF assigned by OSHA can be up to 1000 . Evidence for such a high value has to be demonstrated in testing the protection devices through the use of the manufacturer-recommended fit and seal; loose-fitting helmets and PAPRs have been reported to have the protection factor of 25 . When used properly, PAPRs have higher APFs than both disposable respirators and half-facepiece RERs.
Notably, PAPRs are named according to their fit, such as loose- or tight-fitting, or according to the area covered, such as full-facepiece or half-facepiece. These respirators have different types of fans or blowers with adjustable airflow ranges, and they mainly have high-efficiency particulate air (HEPA) filters with $99.97 \%$ efficiency against MPPS of $0.3 \mu \mathrm{m}$. There is a wide range of products and filters, which makes PAPRs a suitable option for use in healthcare settings. Among all respirators, HEPA filters with tight-fitting full-facepiece PAPRs provide the highest efficiency of filtering (class TM3).

Even though there are few reports about the utilization of RERs in hospital conditions, scientific evidence shows a probability of decreased leakage [28], face-adjusting functionality, fit-securing head straps, and a longlasting elastomeric adaptation to the face. Therefore, it has been suggested that these respirators could be used by HCPs [23]. However, Jannsen et al. [29] emphasized the importance of additional data requirements to evaluate the correlation between leakage, fit-to-face, and sustainability throughout use; these factors were also suggested to be compared with those of disposable FFPs.

Along with the fact that PAPRs with loose-fitting helmets or hood design are more easily worn, they do not require a thorough fit test for leakage control, and can be worn even with facial hair. These characteristics of PAPRs have been described as advantages over RERs. It has also been reported that PAPRs have loose-fitting headgears and allow the face of HCPs to be seen by patients, which enables better communication. Furthermore, parts of PAPRs can be cleaned or changed in the case of a malfunction. The major limiting factor for the utilization of RERs by healthcare institutions is related to concerns about the cleaning and disinfection of such equipment. In a laboratory setting, the reprocessing protocols were defined by Lawrence et al. [30]. They evaluated the effectiveness of this equipment for an influenza pandemic. More specifically, 5 half-facepiece RERs and 3 PAPRs units were tested. 
Forty-one surfaces were contaminated with the influenza virus, following which they were cleaned and disinfected. Lawrence et al. [30] concluded that the methods they explained could be effective in cleaning and disinfecting influenza viruses. Moreover, these data might overcome some concerns regarding the effectiveness of the cleaning and disinfection of reusable respiratory devices such as half- or full-facepiece elastomeric respirators and PAPRs.

Disinfection methods have also been studied, and cleaning protocols have been described for reusable respiratory devices that are intended for use during a pandemic. In the maintenance of PAPRs, chemical substances could damage respirators, so substances such as quaternary amines in oilfield parlance should not be used. Some disinfectants have also been reported as unsuitable and ineffective for disinfection procedures. There are currently no cleaning protocols or SARS-CoV-2 disinfection procedures established for reusable respiratory devices.

Even though there are concerns about the cleaning and disinfection methods of RRPs, these devices provide higher protection factors than disposable filtering respirators, thereby justifying the need for further evaluation or recommendations of reusable respiratory protective equipment to HCPs. In a recent publication by Lee et al. [31], protection against particles of 0.093 and $1.61 \mu \mathrm{m}$, which also covers the size of SARS-CoV-2, was tested for various types of disposable facepiece respirators. Among the tested respirators, nearly $11 \%$ of FFP2 and $28 \%$ of FFP3 respirators showed protection factors below the APF described by the British standard. The protection factors were found to be 11.5-15.9 times higher in FFP respirators than that in surgical masks. Furthermore, a strong correlation between the fit-to-face characteristic and the protection factor was determined [31].

\section{CONCLUSIONS}

This review has investigated considerations in healthcare facilities such that reusable respirators are used as an alternative to disposable respirators in the case of market shortages during the COVID-19 pandemic, and the issues to consider in choosing specific reusable personal respiratory protective equipment. The decision to choose specific equipment should be based not only on the protection factors but also on the overall analysis of specific conditions. The users' training levels, workplace conditions, and work intensity, along with the breathing rate, the amount of body movement, the maintenance of equipment, the hazards posed by substances, viruses or bacteria, and their concentration levels should all be considered and preferably analyzed before selecting respiratory protection equipment. Considering the COVID-19 pandemic conditions, the respiratory protective equipment with higher protection factors have to be provided for HCPs, especially in emergency care units, intensive care units, family primary care units and COVID-19 patient services.

For HCPs, the evidence shown in this article provides an additional support for the utilization of RERs. Such equipment might be less prone to leakages, can provide a better fit, and indicates a better stability compared to disposable FFRs (N95 and similar). By providing higher protection factors, RERs are recommended to be used by HCPs under controlled cleaning and disinfection protocols.

\section{REFERENCES}

1. Coronaviridae Study Group of the International Committee on Taxonomy of Viruses. The species severe acute respiratory syndrome-related coronavirus: classifying 2019-nCoV and naming it SARS-CoV-2. Nat Microbiol. 2020;5(4):536-44, https://doi.org/10.1038/s41564-020-0695-z.

2. Liverman CT, Yost OC, Rogers BME, Clever HL. National Academies of Sciences, Engineering, and Medicine; Health and Medicine Division; Board on Health Sciences Policy; Committee on the Use of Elastomeric Respirators in Health Care. Reusable Elastomeric Respirators in Health Care: Considerations for Routine and Surge Use. Washington (DC): National Academies Press (US); 2018. 
3. Institute of Medicine. Preparing for an influenza pandemic: Personal protective equipment for healthcare workers. Washington, DC: The National Academies Press; 2008.

4. Shaffer RE, Rengasamy S. Respiratory protection against airborne nanoparticles: A review. J Nanopart Res. 2009;11(7):1661, https://doi.org/10.1007/s11051-009-9649-3.

5. Zhu N, Zhang D, Wang W, Li X, Yang B, Song J, et al. A novel coronavirus from patients with pneumonia in China, 2019. N Engl J Med. 2020;382:727-33, https://doi.org/10.1056/ NEJMoa2001017.

6. MacIntyre CR, Wang Q, Rahman B, Seale H, Ridda I, Gao Z, et al. Efficacy of face masks and respirators in preventing upper respiratory tract bacterial colonization and co-infection in hospital healthcare workers. Prev Med. 2014;62:1-7, https://doi.org/10.1016/j.ypmed.2014.01.015.

7. Cole EC, Cook CE. Characterization of infectious aerosols in health care facilities: an aid to effective engineering controls and preventive strategies. Am J Infect Control. 1998;26:45364, https://doi.org/10.1016/s0196-6553(98)70046-x.

8. Stelzer-Braid S, Oliver BG, Blazey AJ, Argent E, Newsome TP, Rawlinson WD, et al. Exhalation of respiratory viruses by breathing, coughing, and talking. J Med Virol. 2009;81:1674-9, https://doi.org/10.1002/jmv.21556.

9. Fennelly KP, Martyny JW, Fulton KE, Orme IM, Cave DM, Heifets LB. Cough-generated aerosols of mycobacterium tuberculosis: a new method to study infectiousness. Am J Resp Crit Care. 2004;169:604-9, https://doi.org/10.1164/rccm.200308-11010C.

10. Blachere FM, Lindsley WG, Pearce TA, Anderson SE, Fisher M, Khakoo R, et al. Measurement of airborne influenza virus in a hospital emergency department. Clin Infect Dis. 2009;48:438-40, https://doi.org/10.1086/596478.

11. Hinds WC. Aerosol Technology: Properties, Behavior and Measurement of Airborne Particles. New York: John Wiley \& Sons; 1999.

12. Lee KW, Liu BYH. On the minimum efficiency and the most penetrating particle size for fibrous filters. J Air Pollut Control Assoc. 1972;30(4):337-81, https://doi.org/10.1080/00022 470.1980 .10464592$.
13. Jung CH, Park H-S, Kim YP. Theoretical study for the most penetrating particle size of dust-loaded fiber filters. Sep $\mathrm{Pu}$ rif Technol. 2013;116:248-52.

14. Floyd KA, Eberly AR, Hadjifrangiskou M. Adhesion of bacteria to surfaces and biofilm formation on medical devices. In: Deng Y, Lv W. editors. Biofilms and Implantable Medical Devices Infection and Control. Woodhead Publishing; 2017. p. 47-95.

15. Mitchell JG, Kogure K. Bacterial motility: links to the environment and a driving force for microbial physics. FEMS Microbiol Ecol. 2006;55:3-16, https://doi.org/10.1111/j.15746941.2005.00003.x.

16. Pu Y, Zheng J, Chen F, Long Y, Wu H, Li Q, et al. Preparation of polypropylene micro and nanofibers by electrostatic-assisted melt blown and their application. Polymers. 2018;10(9):959, https://doi.org/10.3390/polym10090959.

17. Noda T. Native morphology of influenza virions. Front Microbiol. 2011;2:269.

18. Radonovich LJ, Simberkoff MS, Bessesen MT, Brown AC, Cummings DAT, Gaydos CA, et al. N95 respirators vs medical masks for preventing influenza among health care personnel: a randomized clinical trial. JAMA. 2019;322(9): 824-33, https://doi.org/10.1001/jama.2019.11645.

19. Loeb M, Dafoe N, Mahony J, John M, Sarabıa A, Glavin V, et al. Surgical mask vs $\mathrm{n} 95$ respirator for preventing influenza among health care workers: a randomized trial. JAMA. 2009;302(17):1865-71, https://doi.org/10.1001/jama.2009.1466.

20. MacIntyre CR, Cauchemez S, Dwyer DE, Seale H, Cheung P, Browne G, et al. Face mask use and control of respiratory virus transmission in households. Emerg Infect Dis. 2009;15(2):233-41, https://doi.org/10.3201/eid1502.081167.

21. Lai CC, Shih TP, Ko WC, Tang HJ, Hsueh PR. Severe acute respiratory syndrome coronavirus 2 (SARS-CoV-2) and coronavirus disease-2019 (COVID-19): the epidemic and the challenges. Int J Antimicrob Agents. 2020;55(3):105924, https://doi.org/10.1016/j.jiantimicag.2020.105924.

22. MacIntyre CR, Chughtai AA. A rapid systematic review of the efficacy of face masks and respirators against 
coronaviruses and other respiratory transmissible viruses for the community, healthcare workers and sick patients. Int J Nurs Stud. 2020;103629, https://doi.org/10.1016/j.jnurstu. 2020.103629 .

23. Lawrence RB, Duling MG, Calvert CA, Coffey CC. Comparison of performance of three different types of respiratory protection devices. J Occup Environ Hyg. 2006;3(9):46574, https://doi.org/10.1080/15459620600829211.

24. Duling M, Lawrence R, Slaven J, Coffey C. Simulated workplace protection factors for half-facepiece respiratory protective devices. J Occup Environ Hyg. 2007;4(6):420-31, https://doi.org/10.1080/15459620701346925.

25. Cho KJ, Jones S, Jones G, McKay R, Grinshpun SA, Dwivedi A, et al. Effect of particle size on respiratory protection provided by two types of $\mathrm{N} 95$ respirators used in agricultural settings. J Occup Environ Hyg. 2010;7(11):622-27, https:// doi.org/10.1080/15459624.2010.513910.

26. Vo E, Zhuang Z, Horvatin M, Liu Y, He X, Rengasamy S. Respirator performance against nanoparticles under simulated workplace activities. Ann Occup Hyg. 2015;59(8):101221, https://doi.org/10.1093/annhyg/mev042.

27. Centers for Disease Control and Prevention [Internet]. Washington: The Centers; 2020 [cited 2020 Jun 11]. Elastomeric Respirators: Strategies During Conventional and Surge Demand Situations Conventional, Contingency, and Crisis Strategies.
Available from: https://www.cdc.gov/coronavirus/2019-ncov/ hcp/elastomeric-respirators-strategy/index.html.

28. Han DH, Lee J. Evaluation of particulate filtering respirators using inward leakage (IL) or total inward leakage (TIL) testing-Korean experience. Ann Occup Hyg. 2005;49(7):569-74, https://doi.org/10.1093/annhyg/mei034.

29. Janssen L, McCullough NV. Elastomeric, half-facepiece, air-purifying respirator performance in a lead battery plant. J Occup Environ Hyg. 2010;7(1):46-53, https://doi.org/10. 1080/15459620903373537.

30. Lawrence C, Harnish DA, Sandoval-Powers M, Mills D, Bergman M, Heimbuch BK. Assessment of half-mask elastomeric respirator and powered air-purifying respirator reprocessing for an influenza pandemic. Am J Infect Control. 2017; 45(12):1324-30, https://doi.org/10.1016/j.ajic.2017.06.034.

31. Lee SA, Hwang DC, Li HY, Tsai CF, Chen CW, Chen JK. Particle size-selective assessment of protection of European standard FFP respirators and surgical masks against particles-tested with human subjects. J Healthc Eng. 2016; 2016:8572493, https://doi.org/10.1155/2016/8572493.

32. Hawes CL, Rogers BM, Yost O, Liverman CT. National Academies of Sciences, Engineering, and Medicine. Reusable elastomeric respirators in health care: Considerations for routine and surge use. Washington, DC: The National Academies Press; 2019.

This work is available in Open Access model and licensed under a Creative Commons Attribution-NonCommercial 3.0 Poland License - http://creativecommons.org/ licenses/by-nc/3.0/pl/deed.en. 